\title{
Risk factors for eating disorder psychopathology within the treatment seeking transgender population: The role of cross-sex hormone treatment
}

Running head: Eating disorder psychopathology in transgender people

Bethany Alice Jones ${ }^{1,2}$, Emma Haycraft ${ }^{2 *}$, Walter Pierre Bouman ${ }^{1}$, Nicola Brewin ${ }^{3}$, Laurence Claes $^{4,5}$ and Jon Arcelus ${ }^{1,6}$

\footnotetext{
${ }^{1}$ Nottingham Centre for Transgender Health, Nottingham, United Kingdom

${ }^{2}$ School of Sport, Exercise, and Health Sciences, Loughborough University, United Kingdom

${ }^{3}$ Leicestershire Eating Disorder Service, Bennion Centre, Glenfield Hospital, Leicester, United Kingdom

${ }^{4}$ KU Leuven, Faculty of Psychology and Education Sciences, Leuven, Belgium

${ }^{5}$ University of Antwerp, Faculty of Medicine and Health Sciences (CAPRI), Antwerp, Belgium

${ }^{6}$ Institute of Mental Health, School of Medicine, University of Nottingham, Nottingham, United Kingdom
}

* Corresponding author: Dr Emma Haycraft, School of Sport, Exercise and Health Sciences, Loughborough University, Leicestershire, LE11 3TU, Tel. +44(0)1509 228160 , Email: E.Haycraft@lboro.ac.uk

Funding: Bethany Jones was supported by a PhD studentship co-funded by Leicestershire Partnership NHS Trust and Loughborough University. No other sources of funding were used to assist in the preparation of this article. 


\begin{abstract}
Many transgender people experience high levels of body dissatisfaction, which is one of numerous factors known to increase vulnerability to eating disorder symptoms in the cisgender (non-trans) population. Cross-sex hormones can alleviate body dissatisfaction so might also alleviate eating disorder symptoms. This study aimed to explore risk factors for eating disorder symptoms in transgender people and the role of cross-sex hormones. Individuals assessed at a national transgender health service were invited $(\mathrm{N}=563)$. Transgender people not on cross-sex hormones reported higher levels of eating disorder psychopathology than people who were. High body dissatisfaction, perfectionism, anxiety symptoms and low self-esteem were risk factors for eating psychopathology but, after controlling for these, significant differences in eating psychopathology between people who were and were not on cross-sex hormones disappeared. Cross-sex hormones may alleviate eating disorder psychopathology. Given the high prevalence of transgender identities, clinicians at eating disorder services should assess for gender identity issues.
\end{abstract}

Key words: transgender, eating disorder psychopathology, risk factors, cross-sex hormones, body dissatisfaction 
Eating disorder psychopathology in transgender people

\section{Introduction}

Eating disorder psychopathology, which includes restrictive eating, binge eating and compensatory behaviours (e.g., self-induced vomiting, misuse of diet pills and laxatives), has been found to be more prevalent among adolescent girls and young adult women compared to men (e.g., Duncan, Ziobrowski, \& Nicol, 2017; Fairburn \& Harrison, 2003). Body dissatisfaction (i.e., the negative evaluation of one's appearance; which is also more prevalent among adolescents and young people), has consistently been associated with eating disorder psychopathology in both females and males (e.g., Keel, Fulkerson, \& Leon, 1997; Stice \& Shaw, 2002; Wang, Lydecker, \& Grilo, 2017). Body dissatisfaction is influenced by Western society's view of beauty (e.g., Fitzsimmons-Craft, 2011). As a consequence, women who are dissatisfied with their bodies often strive to obtain a thin body, while men are more likely to strive to obtain a muscular physique (e.g., Grogan, 2016; McCreary \& Sasse, 2000). There are certain populations that have been found to be at increased risk of high levels of body dissatisfaction, such as the lesbian, gay, bisexual and transgender (LGBT) community (e.g., Calzo, Blashill, Brown, \& Argenal, 2017; McClain \& Peebles, 2016; Morgan \& Arcelus, 2009). Within this group, transgender people are particularly vulnerable to body dissatisfaction due to the distress and incongruence they experience with their gender and body, yet this population is severely under researched in relation to eating disorders psychopathology (Jones, Haycraft, Murjan, \& Arcelus, 2016; Witcomb et al., 2015).

Transgender people experience incongruence between their gender assigned at birth (determined from their sex characteristics (i.e., genitals)) and the gender they identify with. Transgender men are assigned female at birth but identify as male, while transgender women are assigned male at birth but identify as female (Arcelus \& Bouman, 2017a; Bouman et al., 2017a). Cisgender people (non-transgender) do not experience such incongruence. Prior to 
undergoing gender affirming medical interventions (e.g., cross-sex hormone treatment (CHT), gender affirming surgery), many treatment seeking transgender people are dissatisfied with their body shape and/or weight, which may put them at risk of developing an eating disorder (Witcomb et al., 2015). It has been hypothesised that it is the body dissatisfaction (a common feature of eating disorder psychopathology), linked to the wish to achieve a masculine or feminine body ideal, which influences the development of eating disorder psychopathology, specifically drive for thinness and bulimia, among transgender people (Ålgars, Alanko, Santtila, \& Sandnabba, 2012; Bouman \& Arcelus, 2016; Khoosal, Langham, Palmer, Terry, \& Minajagi, 2009). In addition, it has also been hypothesised that the wish to stop menstruation and puberty, as well as not wanting to develop a feminine body shape (such as the development of breasts), can also play a role in the development of an eating disorder in transgender males (Bouman \& Arcelus, 2016). This may explain why disordered eating has been found to be prevalent in transgender adolescents (Watson, Veale, \& Saewyc, 2017). For example, Diemer, Grant, Munn-Chernoff, Patterson and Duncan (2015) found that transgender adolescents more frequently self-reported an eating disorder diagnosis in the past year (15.84\%), and presented with eating disorder symptoms such as the use of diet pills (13.50\%), self-induced vomiting and laxative abuse (15.61\%), compared to cisgender adolescents.

As well as presenting to transgender health services with symptoms of an eating disorder, transgender people may initially present to eating disorder services. Case studies have reported on individuals who first present with eating disorder symptoms (e.g., food restriction, vomiting and body image distortion) without disclosing their transgender identity which, through exploration, has later been expressed as a desire to achieve a masculine or feminine body (different to the body associated with their gender assigned at birth) and, 
hence, identified as secondary to their gender identity (e.g., Couturier, Pindiprolu, Findlay, \& Johnson, 2015; Winston, Acharya, Chaudhuri, \& Fellowes, 2004). These findings are concerning considering that gender incongruence is not routinely assessed within eating disorder services given that the prevalence of transgender people is considered to be low. However, recently the prevalence of transgender people has increased and there has been a significant increase in demand for transgender health services across Europe and North America (Aitken et al., 2015; Arcelus et al., 2015; de Vries, Kreukels, T’Sjoen, Ålgars, \& Mattila, 2015; House of Commons, 2016; Jones et al., 2017). Therefore, gender incongruence may need to be considered by clinicians working at eating disorder services.

Within the cisgender population, several factors (such as body dissatisfaction (e.g., Keel et al., 1997; Stice \& Shaw, 2002), high levels of perfectionism (e.g., Egan, Wade, \& Shafran, 2011; Tchanturia, Larsson, \& Adamson, 2016), the existence of interpersonal problems (e.g., Arcelus, Haslam, Farrow, \& Meyer, 2013), low self-esteem (Dakanalis et al., 2016), symptoms of anxiety and depression (e.g., Brechan \& Kvalem, 2015; DeBoer \& Smits, 2013; Fairburn, Cooper, \& Shafran, 2003; Harrison, Sullivan, Tchanturia, \& Treasure, 2009; Puccio et al., 2017) have been identified as being associated with eating disorder psychopathology and found to increase the risk of developing an eating disorder. Body dissatisfaction has consistently been found to be associated with eating disorder psychopathology (e.g., Keel et al., 1997; Stice \& Shaw, 2002). Dissatisfaction with one's body has been described as a core feature, but not sufficient to completely explain the development of eating disorders (Polivy \& Herman, 2002). The relationship between eating disorder psychopathology and body dissatisfaction has been found to be complex as cognitive behavioural and emotional regulation theories of eating disorders have suggested that negative emotions, such as anxiety and depression, as well as self-esteem, mediate the relationship between body dissatisfaction 
and eating disorder psychopathology (e.g., Brechan \& Kvalem, 2015; DeBoer \& Smits, 2013; Fairburn et al., 2003; Harrison et al., 2009). Anxiety symptomatology has also been found to partially mediate the association between self-orientated perfectionism (a trait often associated with eating disorders; Egan et al., 2011) and eating disorder psychopathology (Egan et al., 2013), which suggests that anxiety plays a role in eating disorder development. Furthermore, interpersonal difficulties have also been linked to behaviours associated with eating disorders within the cisgender population (e.g., Arcelus et al., 2013).

Factors associated with, and found to mediate, eating disorder psychopathology in the cisgender population may be particularly pertinent among transgender people. This is because research has consistently shown treatment seeking transgender people to report high levels of mental health problems, such as anxiety and depression (e.g., Arcelus, Claes, Witcomb, Marshall, \& Bouman, 2016; Bouman, Davey, Meyer, Witcomb, \& Arcelus, 2016a; Bouman et al., 2017a; Dhejne, Van Vlerken, Heylens, \& Arcelus, 2016; Millet, Longworth, \& Arcelus, 2017), perfectionism (Khoosal et al., 2009), and interpersonal problems (Davey, Bouman, Meyer, \& Arcelus, 2015) in comparison to cisgender people. Therefore these factors may be important when exploring risk factors for eating disorder psychopathology within the transgender population.

Once a medical transition has been initiated (e.g., CHT and gender affirming surgery), body dissatisfaction has been found to significantly improve in transgender adults (e.g., de Vries, Steensma, Doreleijers, \& Cohen-Kettenis, 2011, de Vries et al., 2014; Fisher et al., 2014; van de Grift et al., 2016, 2017) and, therefore, these interventions may reduce the risk of developing an eating disorder or help to alleviate eating disorder symptoms. Although research is limited (one study date), eating disorder symptoms have been found to reduce 
once transgender women progress through their medical transition (Khoosal et al., 2009). However, this study only considered the role of surgery and not CHT. The study is also limited by the small sample size $(\mathrm{N}=40)$ and only recruiting transgender women. In light of this, the current study was concerned with exploring the role of CHT only and recruiting a larger sample comprising both men and women. In addition to this, this study was concerned with exploring risk factors in transgender people yet to undergo a medical transition as this vulnerable population may first present to eating disorder services (without disclosing their transgender identity). As the cisgender literature suggests that eating disorders are complex and multifactorial this is also likely to be the case within the transgender population. Variables that can mediate between identified risk factors and eating disorder psychopathology will be explored. These analyses within the transgender population are important to determine through which mechanisms gender affirming medical interventions (e.g., CHT) are capable of alleviating eating disorder symptoms. Taking into consideration some of the limitations of previous research, the study had three specific aims:

1. To examine the role of CHT in eating disorder symptoms by determining whether there is a difference in eating disorder psychopathology (drive for thinness and bulimia) between a large sample of transgender people who are or who are not on CHT.

2. To explore risk factors (age, assigned gender, body dissatisfaction, perfectionism, interpersonal problems, self-esteem, anxiety, and depression) associated with eating disorder psychopathology in transgender people who are not on CHT.

3. To explore factors that mediate the relationship between identified risk factors and eating disorder psychopathology (drive for thinness and bulimia) in transgender people who are not on CHT. 
Based on previous research it was first hypothesised that transgender people on CHT would have lower levels of eating disorder psychopathology compared to participants who are not on cross-sex hormones (e.g., Fisher et al., 2014). Second, it was hypothesised that younger age, identifying as female (because transgender people adopt and perform the social gender role (i.e., behaviours, attributes) associated with their experienced gender identity), higher levels of body dissatisfaction, anxiety, depression, perfectionism, interpersonal problems and lower levels of self-esteem would be risk factors for eating disorder psychopathology in transgender people who are not on CHT. Third, based on the centrality of body dissatisfaction to both gender incongruence (e.g., Jones et al., 2016) and eating disorders (e.g., Stice \& Shaw, 2002), it was hypothesised that if a significant relationship was found between body dissatisfaction and eating disorder psychopathology (addressed in aim 2), then the other identified risk factors would mediate this relationship in people who are not on CHT. 


\section{Method}

Participants and recruitment

All patients offered an assessment at a national transgender health service in the United Kingdom (UK) between 2012 and 2015 were invited to take part in the study. This transgender health service offers assessment and gender affirming medical interventions to adults aged 17 and over who are considering, or wish to, medically transition. Patients are assessed by a transgender health professional, which could be a psychiatrist, psychologist or nurse specialist. The assessment process usually occurs over three appointments, with two different clinicians. During the third appointment, patients are invited to bring a relative or friend with them. In total, 586 patients were invited for assessment during the study period and $563(96 \%)$ agreed to participate (see Table 1 for characteristics of the whole sample). While all participants were recruited at the point of assessment, some people had initiated CHT prior to assessment at this service $(n=139,24.7 \%)$. Some participants may have initiated this intervention as their care was transferred from the child and adolescent gender identity development service and others might have obtained CHT through private health providers or via the Internet (Mepham, Bouman, Arcelus, Hayter, \& Wylie, 2014). Table 1 also presents descriptive statistics separately for people who were and were not on CHT. In order to have an overall representation of patients attending a national transgender health service, no exclusion criteria were applied.

\section{Insert Table 1 here}

\section{Procedure}

Before initial assessment, participants were invited to complete socio-demographic questions and a range of self-report measures. This was part of a larger study for which ethical approval was obtained from the National Health Service (NHS) ethics committee and from the 
Research and Development Department from the Nottinghamshire Healthcare NHS Foundation Trust in accordance with Health Research Authority guidance (HRA, 2013). Patients were informed that they could request a summary of the research findings on completion of the project. No patients chose to do this.

\section{Measures}

Socio-demographic information: Participants were asked to provide information about their age, gender assigned at birth, and stage of medical transition pre-assessment (e.g., whether they were on CHT or not). They were then invited to complete the following selection of self-report measures.

\section{Eating Disorder Inventory-2 (EDI-2; Garner, 1991)}

This questionnaire is commonly used to assess behaviours and psychological traits associated with eating disorder psychopathology. It has 11 subscales; three which assess eating-related symptoms (drive for thinness, bulimia, and body dissatisfaction) and eight which are associated with eating-related psychological features common in eating disorders (ineffectiveness, perfectionism, interpersonal distrust, interoceptive awareness, maturity fears, asceticism, impulse regulation, and social insecurity). In the current study, the drive for thinness and bulimia subscales were used to measure eating disorder psychopathology. The body dissatisfaction, perfectionism and interpersonal distrust subscales were also used. Responses are rated on a 6-point Likert scale anchored from 'never' to 'always' and a higher score indicates a higher level of eating disorder psychopathology. All the subscales have previously been found to have good reliability among patients with an eating disorder and the general population (e.g., Nevonen, Clinton, \& Norring, 2006). In the current study, the Cronbach alpha values were as follows: drive for thinness $(\alpha=.85)$, bulimia $(\alpha=.83)$, body 
dissatisfaction $(\alpha=.85)$, perfectionism $(\alpha=.70)$ and interpersonal distrust $(\alpha=.80)$, showing that all had good reliability.

Rosenberg Self-Esteem Scale (RSE; Rosenberg, 1965)

This is a 10-item self-report measure that assesses self-esteem using a 4-point Likert scale ('strongly agree' $=3$ to 'strongly disagree' $=0$ ). It produces a global score, which is calculated by summing the scores from the individual items. A high score indicates a higher self-esteem (highest possible score is 30 ). The measure has been validated and has excellent reliability ( $\alpha=0.88-0.90$; Robins, Hendin, \& Trzesniewski, 2001). In the current study, the reliability was also excellent $(\alpha=.92)$.

\section{Hospital Anxiety and Depression Scale (HADS; Zigmond \& Snaith, 1983)}

This measure has 14 items in total, seven which relate to anxiety (HADS-A) and seven which relate to depression (HADS-D). The HADS-A and HADS-D subscale scores are calculated by summing scores from the individual items. Participants are asked to rate their responses on a 4-point Likert Scale ('not at all' = 1 to 'most of the time' = 3). For each subscale, scores between 0-7 are considered normal, scores between 8-10 are considered borderline clinical, and scores of 11 and above are considered clinically relevant (Snaith, 2003). The highest score possible is 21 for each subscale. The measure has good reliability in somatic, psychiatric and primary care patients as well as in the general population (Bjelland, Dahl, Haug, \& Neckelmann, 2002). In the current study, both the anxiety $(\alpha=.84)$ and depression $(\alpha=.77)$ subscales had good reliability.

\section{Data analysis}


Data were analysed using SPSS 23 (IBM, 2015). The data were not normally distributed and therefore non-parametric tests were used when possible. Missing data were excluded using the pairwise method apart from in the Mann-Whitney $U$ analysis where the test-by-test method was employed. Before the main analysis, descriptive analysis was conducted. For the first aim, a Mann-Whitney U test was conducted to determine whether there was a difference in eating disorder psychopathology between people who had taken CHT and those who had not. For the second aim, preliminary one-tailed Spearman Rho correlations were conducted between the dependent variables (drive for thinness and bulimia) and independent variables (age, gender assigned at birth, anxiety, depression, self-esteem, body dissatisfaction, interpersonal distrust and perfectionism). As categorical variables cannot be entered into correlational analysis, a dummy variable was created for gender assigned at birth. The function of the Spearman's Rho correlations was to determine which variables significantly correlated with the dependent variables and, consequently, to include only these variables in subsequent regression analysis to increase its robustness. Multicollinearity was not a cause for concern as no variable correlated at $r \geq .90$ with the outcome variables (Pallant, 2010). As multiple comparisons were conducted, Bonferroni corrections were used for the correlation analysis $(.05 \div 16=.003)$. To determine which variables were able to explain the most variance in eating disorder psychopathology (drive for thinness and bulimia) in people who were yet to take CHT, stepwise multiple linear regression analysis was conducted. Once the risk factors had been established an ANCOVA was conducted to determine whether there was a significant difference in eating disorder symptoms between people who were and were not on $\mathrm{CHT}$ after controlling for the risk factors identified in the multiple linear regression analysis. For the third aim, mediation analysis was conducted to better understand the mechanisms that underlie the relationship between the independent variable (hypothesised to be body dissatisfaction) and eating disorder psychopathology (drive for thinness and 
Eating disorder psychopathology in transgender people

bulimia). Mediation analysis was conducted using the PROCESS macro in SPSS (Hayes, 2013). Model 4, which uses the bias-corrected bootstrap confidence interval method, was employed. The level of significance used for all the analysis was $p<.05$. 


\title{
Results
}

\section{Aim 1: Differences in eating disorder psychopathology between people who were on cross-sex hormones and those who were not}

A Mann-Whitney U test was conducted to determine whether participants who were $(\mathrm{n}=139)$ and were not $(\mathrm{n}=416)$ on CHT differed in levels of drive for thinness and bulimia. The analysis demonstrated that transgender people who were not on CHT reported significantly higher levels of drive for thinness and bulimia compared to participants who were on CHT (see Table 2).

Mann-Whitney U tests also showed that people who were not on CHT were significantly younger, had higher levels of body dissatisfaction and interpersonal distrust, more symptoms of anxiety and depression, and lower levels of self-esteem than participants who were on CHT (see Table 2). There was no significant difference in levels of perfectionism between the two groups. A Pearson Chi-Squared test was conducted to explore differences in gender assigned at birth based on CHT use and this test was not significant $\left(\chi^{2}(1)=3.01, p=.083\right)$ suggesting that gender assigned at birth is independent of CHT.

\section{Insert Table 2 here}

\begin{abstract}
Aim 2: Risk factors of eating disorder psychopathology in people who were not on CHT Drive for thinness: Body dissatisfaction, high levels of perfectionism, the experience of interpersonal distrust, symptoms of anxiety and depression and low self-esteem were all significantly correlated with drive for thinness in people who were not on CHT $(n=416$; see Table 3) and were therefore entered into the subsequent stepwise regression analysis.
\end{abstract}


Eating disorder psychopathology in transgender people

\section{Insert Table 3 here}

Overall, the stepwise regression model was significant and the significant variables explained $30 \%$ of the total variance of drive for thinness (see Table 4). Higher levels of body dissatisfaction made the largest contribution to the variance followed by high levels of perfectionism and anxiety symptoms (see Table 4). The average VIF (variance inflation factor) for this model was 1.10 and the average tolerance was 0.91 . The average VIF was not greater than 10 (Myers, 1990) and the average tolerance was not below 0.10 (Menard, 1995), which indicates that the assumptions of multicollinearity for this model were met and hence the variables were not too highly correlated.

Bulimia: Body dissatisfaction, high levels of perfectionism, the experience of interpersonal distrust, symptoms of anxiety and depression and low self-esteem were all significantly correlated with bulimia in people who were not on cross-sex hormones $(n=416$; see Table 3$)$. These six variables were therefore entered into a subsequent stepwise regression model. Overall, this model was significant and explained $25 \%$ of the total variance in bulimia (see Table 4). Low self-esteem made the largest contribution to the variance, followed by high levels of perfectionism, body dissatisfaction and symptoms of anxiety (see Table 4). The average VIF for this model was 1.38 and the average tolerance was 0.75 indicating that there is no multicollinearity within the model (Menard, 1995; Myers, 1990).

\section{Insert Table 4 here}

After determining the risk factors for eating disorder psychopathology in people yet to commence cross-sex hormones $(n=416)$, an ANCOVA was conducted to determine whether there was a significant difference in eating disorder psychopathology between people who 
were $(n=139)$ and were not $(n=416)$ on CHT, after controlling for the identified risk factors. It was found that there was no longer a significant difference in drive for thinness between people who were and were not on CHT when body dissatisfaction, perfectionism and symptoms of anxiety were controlled for $(F(1,538)=.35, p=.885)$. It was also found that there was no longer a significant difference in levels of bulimia between people who were and were not on cross-sex hormones after self-esteem, perfectionism, body dissatisfaction and symptoms of anxiety were controlled for $(F(1,529)=.03, p=.868)$.

\section{Aim 3: Exploring the mediators of the relationship between risk factors and eating disorder psychopathology in people who were not on CHT}

In addressing aim 2, it was found that high levels of body dissatisfaction were a risk factor for both drive for thinness and bulimia. Due to the centrality of body dissatisfaction in both gender incongruence (e.g., Jones et al., 2016, van de Grift et al., 2016, 2017) and eating disorders (e.g., Stice \& Shaw, 2002), mediators of the relationship between body dissatisfaction and eating disorder psychopathology were explored for people who had not yet commenced CHT $(n=416)$. The remaining risk factors identified in aim 2 were explored as mediators (perfectionism, symptoms of anxiety and self-esteem). Mediation occurs when the bootstrapped lower and upper confidence intervals do not include zero.

Perfectionism (model 1) and symptoms of anxiety (model 2) were explored separately as mediators of the relationship between body dissatisfaction and drive for thinness. Self-esteem (model 3), perfectionism (model 4) and anxiety (model 5) were explored separately as mediators of the relationship between body dissatisfaction and bulimia. Figure 1 demonstrates the five different models analysed through the direct and indirect effects. As can be seen by the unstandardized beta model coefficients $(a, b, c)$ in Table $5, \mathrm{X}$ (the 
independent variable; body dissatisfaction) always significantly predicted $\mathrm{M}$ (the mediator) depicted by pathway (a), and M always significantly predicted $\mathrm{Y}$ (the outcome variable; drives for thinness or bulimia) depicted by pathway $(b)$, in all five models analysed. The direct effect (X-Y; depicted by pathway $c$ ) was also significant in all models (see Table 5). For the indirect effect, a bias-corrected bootstrap confidence interval based on 5000 bootstrap sample was explored. As the bootstrapped lower and upper confidence intervals did not include zero it can be concluded that perfectionism (model 1) and symptoms of anxiety (model 2) each significantly mediated the relationship between body dissatisfaction and drive for thinness. This indicates that the relationship between body dissatisfaction and drive for thinness can be explained by the presence of perfectionism and anxiety symptoms. In addition, self-esteem (model 3), perfectionism (model 4) and symptoms of anxiety (model 5) each mediated the relationship between body dissatisfaction and bulimia (see Table 5). This indicates that the relationship between body dissatisfaction and bulimia can be explained by the low self-esteem, perfectionism and anxiety symptoms. 
Eating disorder psychopathology in transgender people

\section{Discussion}

This study aimed to understand the risk factors for eating disorder psychopathology within the transgender population, as well as the role of CHT in eating disorder psychopathology. The current study found that transgender people who were on CHT had significantly lower levels of eating disorder symptoms than transgender people who were not. When comparing this finding to previous literature, people within the current study who were on CHT presented with similar levels of eating disorder psychopathology compared to the general population (Witcomb et al., 2015). In contrast, transgender people in the current study who were not on CHT presented with higher levels of eating psychopathology than is found within the general population (Witcomb et al., 2015). When the current study's finding and previous research are considered together, it suggests that CHT may be able to alleviate eating disorder psychopathology, which is in keeping with previous research (Fisher et al., 2014; Khoosal et al., 2009) and case studies (Couturier et al., 2015; Winston et al., 2004) that have supported the notion that eating disorder psychopathology in transgender people is secondary to gender incongruence.

This study is novel in that it aimed to understand why CHT might alleviate eating disorder symptoms by exploring risk factors in transgender people yet to undergo a medical transition. The current study found that high levels of body dissatisfaction, perfectionism, symptoms of anxiety, and low self-esteem were all risk factors for eating disorder psychopathology as reported in the cisgender literature (e.g., Brechan \& Kvalem, 2013; Dakanalis et al., 2016; Egan et al., 2011; Fairburn et al., 2003; Keel et al., 1997; Puccio et al., 2017; Tchanturia et al., 2016). Once the identified risk factors for eating disorder psychopathology were controlled for, there was no longer a significant difference in eating disorder symptoms between people who were and were not on $\mathrm{CHT}$. This finding suggests that $\mathrm{CHT}$ alleviates 
eating disorder symptoms as it reduces levels of body dissatisfaction, perfectionism, symptoms of anxiety and increases self-esteem.

Within the cisgender literature, body dissatisfaction has been described as a core feature of though not sufficient to adequately explain - eating disorder symptoms (Polivy \& Herman, 2002) and, consequently, other factors have been found to mediate the relationship between body dissatisfaction and eating disorder psychopathology (e.g., Brechan \& Kvalem, 2015; DeBoer \& Smits, 2013; Fairburn et al., 2003; Harrison et al., 2009). This also appears to be the case within the transgender population as the current study found high levels of perfectionism and symptoms of anxiety to mediate the relationship between body dissatisfaction and drive for thinness. Additionally, low self-esteem, high levels of perfectionism and symptoms of anxiety were found to mediate the relationship between body dissatisfaction and bulimia in transgender individuals. These findings help to clarify the mechanisms through which CHT might be able to alleviate eating disorder symptoms. They suggest that CHT primarily alleviates high body dissatisfaction, which in turn reduces levels of perfectionism and symptoms of anxiety, and increases self-esteem. In combination, these factors then appear to alleviate eating disorder symptoms. This is the first study with transgender people that has been able to indicate how cross-sex hormones alleviate eating disorder symptoms, although this finding needs to be replicated with longitudinal research.

Clinicians working in eating disorder services should routinely assess gender identity issues as this is where transgender people may first present due to experiencing high levels of body dissatisfaction and eating disorder symptoms that are secondary to gender incongruence. Such patients should be referred to transgender health services as this study has shown the positive role that $\mathrm{CHT}$ plays in eating disorder symptoms. CHT is likely to be more effective 
than interventions offered at eating disorder services in these circumstances (Ewan, Middleman, \& Feldmann, 2014). However, there are likely to be a small number of patients that also require eating-related interventions. To determine whether this is suitable, the role of eating disorder psychopathology will need to be assessed. In our clinical experience, the presence of eating disorder psychopathology, such as food restriction, is engaged in to stop the development of secondary sex characteristics that are related to the individual's assigned gender, such as breast development or menstruation. However, in some cases, CHT alone may not be enough to reduce eating disorder psychopathology and clinicians at transgender health and eating disorder services may need to work together to alleviate eating disorder psychopathology whilst also facilitating access to gender affirming medical interventions.

When patients are referred to transgender health services with symptoms of eating disorders, clinicians might be reluctant to accept such patients onto the treatment programme until these issues are resolved. The findings of the current study indicate that for patients presenting with high levels of eating disorder symptoms (that are secondary to gender identity issues), timely initiation of CHT may likely reduce these symptoms, as well as their gender incongruence. Given the existence of significant barriers to accessing transgender health care (Bouman \& Richards, 2013; Jones et al., 2017; Kanamori \& Cornelius-White, 2016; Scheim, Zong, Giblon, \& Bauer, 2017), it is imperative that access to these services is increased to minimise the risk of eating disorder psychopathology. In addition, although gender affirming medical interventions alleviate body dissatisfaction (a core feature of eating disorder psychopathology) for many, patients who report very high body dissatisfaction pre-gender affirming medical interventions have been found to continue to do so post-gender affirming medical interventions (van de Grift et al., 2017). Clinicians at transgender health services must consider that these patients (who report high body dissatisfaction post-gender affirming 
interventions) may be vulnerable to eating disorder psychopathology and therefore may require eating-related interventions.

Within the current study, neither age or gender (assigned at birth) were found to be risk factors for eating disorder psychopathology within treatment seeking transgender people who were yet to commence CHT. This contrasts with research within the cisgender population which has found adolescents and young adult females to be at greater risk than males and older people (e.g., Fairburn \& Harrison, 2003; Zeiler et al., 2016) and was despite the current study finding that people who were yet to commence CHT were significantly younger (and reported more eating disorder symptoms) than people who had initiated CHT. Previous research with transgender people has found transgender men (assigned female at birth) to report very high levels of body dissatisfaction (a common feature of eating disorder psychopathology) that were comparable to cisgender men with an eating disorder (Witcomb et al., 2015). This finding was not replicated when transgender women were compared to cisgender women with an eating disorder (Witcomb et al., 2015). Therefore, although gender may not be a risk factor for eating disorder symptoms within the transgender population, clinicians in both eating disorder and transgender health services should be mindful that levels of body dissatisfaction among people assigned female at birth may mean that the prevalence of eating disorder symptoms is higher than in people assigned male at birth.

For the first time, the current study has identified multiple risk factors for eating disorder psychopathology within a large sample of treatment seeking transgender people. In addition to this, the alleviating role that CHT plays in eating disorder symptoms has been recognised. This is in contrast to previous research, which has found levels of eating disorder symptoms in the transgender population to be higher than in the general population without 
understanding why (Witcomb et al., 2015). However, the following limitations should be considered. First, this study is cross-sectional and therefore causality cannot be determined. Risk factors need to be explored with further longitudinal research. Second, the group sizes within the comparative analysis were different which might have impacted on the findings. Finally, analysis was conducted in relation to gender assigned at birth. The majority of transgender people will transition within the binary gender system (i.e., man or woman) but there are increasing numbers of transgender people who identify outside the binary gender system (i.e., gender neutral, non-gender, bigender, third gender) or are fluid with their gender identity (Arcelus \& Bouman, 2017a). Therefore, future research should be concerned with transgender people who identify as a woman, a man, and outside the binary gender system.

In conclusion, transgender people who were not on CHT reported more eating disorder symptoms than transgender people who were on CHT. The findings suggest that CHT may be able to alleviate eating disorder symptoms primarily through positively impacting on body dissatisfaction (i.e., increasing body satisfaction) which, in turn, reduces levels of perfectionism and symptoms of anxiety and increases self-esteem. Clinicians working at eating disorder services should incorporate the assessment of gender identity issues within their clinical practice and refer patients with such issues to transgender health services so that they can be evaluated for CHT. 
Acknowledgments: We would like to thank all research participants, who have given their time generously and freely for this project. 
Eating disorder psychopathology in transgender people

\section{References}

Aitken, M., Steensma, T.D., Blanchard, R., VanderLaan, D.P., Wood, H., Fuentes, A., ... Zucker, K.J. (2015). Evidence for an altered sex ratio in clinic-referred adolescents with gender dysphoria. Journal of Sexual Medicine, 12, 756-763. doi: 10.1111/jsm.12817

Ålgars, M., Alanko, K., Santtila, P., \& Sandnabba, N. K. (2012). Disordered eating and gender identity disorder: A qualitative study. Eating Disorders, 20(4), 300-311. doi: http://dx.doi.org/10.1080/10640266.2012.668482

Arcelus, J., \& Bouman, W.P. (2017). Language and Terminology. Chapter 1. In: W.P. Bouman \& J. Arcelus (Eds.). The Transgender Handbook - A Guide for Transgender People, their Families and Professionals. New York: Nova Publishers.

Arcelus, J., Bouman, W.P., Witcomb, G.L., Van De Noortgate, W., Claes, L., \& FernandezAranda, F. (2015). Systematic review and meta-analysis of prevalence studies in transsexualism. European Psychiatry, 30(6), 807-815. doi:

https://doi.org/10.1016/j.eurpsy.2015.04.005

Arcelus, J., Claes, L., Witcomb, G. L., Marshall, E., \& Bouman, W. P. (2016). Risk factors for non-suicidal self-injury among trans youth. Journal of Sexual Medicine, 13(3), 402412. doi: https://doi.org/10.1016/j.jsxm.2016.01.003

Arcelus, J., Haslam, M., Farrow, C., \& Meyer, C. (2013). The role of interpersonal functioning in the maintenance of eating psychopathology: A systematic review and testable model. Clinical Psychology Review, 33(1), 156-167. doi: https://doi.org/10.1016/j.cpr.2012.10.009

Bjelland, I., Dahl, A. A., Haug, T. T., \& Neckelmann, D. (2002). The validity of the Hospital Anxiety and Depression Scale: an updated literature review. Journal of Psychosomatic Research, 52(2), 69-77.doi: https://doi.org/10.1016/S0022-3999(01)00296-3 
Bouman, W. P., \& Arcelus, J. (2016). Body dissatisfaction and maladaptive eating behaviors among people with gender dysphoria. National Eating Disorder Information Centre BULLETIN, 31(2), 1-4.

Bouman, W.P., Claes, L., Brewin, N., Crawford, J.R., Millet, N., Fernandez-Aranda, F., \& Arcelus, J. (2017). Transgender and anxiety: A comparative study between transgender people and the general population. International Journal of Transgenderism, 18(1), 1626.doi: http://dx.doi.org/10.1080/15532739.2016.1258352

Bouman, W. P., Davey, A., Meyer, C., Witcomb, G. L., \& Arcelus, J. (2016). Predictors of psychological well-being among treatment seeking transgender individuals. Sexual and Relationship Therapy, 31(3), 359-375. doi:

http://dx.doi.org/10.1080/14681994.2016.1184754

Bouman, W.P. \& Richards, C. (2013). Diagnostic and Treatment Issues for People with Gender Dysphoria in the United Kingdom. Sexual and Relationship Therapy, 28(3), 165171. doi: http://dx.doi.org/10.1080/14681994.2013.819222

Bouman, W.P., Suess Schwend, A., Motmans, J., Smiley, A., Safer, J.D., Deutch, M.B., ... Winter, S. (2017). Language and Transgender Health. International Journal of Transgenderism, 18(1), 1-6.

Brechan, I., \& Kvalem, I. L. (2015). Relationship between body dissatisfaction and disordered eating: mediating role of self-esteem and depression. Eating Behaviors, 17, 4958. doi: https://doi.org/10.1016/j.eatbeh.2014.12.008

Calzo, J. P., Blashill, A. J., Brown, T. A., \& Argenal, R. L. (2017). Eating Disorders and Disordered Weight and Shape Control Behaviors in Sexual Minority Populations. Current Psychiatry Reports, 19(8), 49. doi: 10.1007/s11920-017-0801-y 
Couturier, J., Pindiprolu, B., Findlay, S., \& Johnson, N. (2015). Anorexia nervosa and gender dysphoria in two adolescents. International Journal of Eating Disorders, 48(1), 151-155. doi: 10.1002/eat.22368

Dakanalis, A., Timko, A., Serino, S., Riva, G., Clerici, M., \& Carrà, G. (2016). Prospective Psychosocial Predictors of Onset and Cessation of Eating Pathology amongst College Women. European Eating Disorders Review, 24(3), 251-256. doi: 10.1002/erv.2433.

Davey, A., Bouman, W. P., Meyer, C., \& Arcelus, J. (2015). Interpersonal Functioning Among Treatment-Seeking Trans Individuals. Journal of Clinical Psychology, 71(12), 1173-1185. doi: 10.1002/jclp.22209

DeBoer, L. B., \& Smits, J. A. (2013). Anxiety and disordered eating. Cognitive Therapy and Research, 37(5), 887-889. doi: 10.1007/s10608-013-9565-9

de Vries, A. L. C., Kreukels, B. P. C., T’Sjoen, G., Ålgars, M. \& Mattila, A. (2015). Increase of referrals to gender identity clinics: A European trend? Characteristics and Hypotheses. In: Transgender Healthcare in Europe - Book of Abstracts. Ghent, Belgium: European Professional Association of Transgender Health (EPATH). Retrieved from: http://epath.eu/wp-content/uploads/2014/07/EPATH-2015-Book-of-Abstracts.pdf

de Vries, A. L. C., Mcguire, J. K., Steensma, T. D., Eva, C. F., Doreleijers, T. A. H., \& Cohen-Kettenis, P. T. (2014). Young adult psychological outcome after puberty suppression and gender reassignment. Paediatrics, 134(4), 696-704. doi: 10.1542/peds.2013-2958

de Vries, A. L. C., Steensma, T. D., Doreleijers, T. A. H., \& Cohen-Kettenis, P. T. (2011). Puberty suppression in adolescents with gender identity disorder: A prospective follow-up study. Journal of Sexual Medicine, 8(8), 2276-2283. doi: 10.1111/j.17436109.2010.01943.x 
Diemer, E. W., Grant, J. D., Munn-Chernoff, M. A., Patterson, D., \& Duncan, A. E. (2015). Gender identity, sexual orientation, and eating-related pathology in a national sample of college students. Journal of Adolescent Health, 57(2), 144-149. doi:

https://doi.org/10.1016/j.jadohealth.2015.03.003

Dhejne, C., Van Vlerken, R., Heylens, G., \& Arcelus, J. (2016). Mental health and gender dysphoria: A review of the literature. International Review of Psychiatry, 28(1), 44-57. doi: http://dx.doi.org/10.3109/09540261.2015.1115753

Duncan, A.E., Ziobrowski, H.N., \& Nicol, G. (2017). The prevalence of past 12-month and lifetime DSM-IV eating disorders by BMI Category in US Men and Women. European Eating Disorders Review, 25(3), 165-171.

Egan, S. J., Wade, T. D., \& Shafran, R. (2011). Perfectionism as a trans-diagnostic process: A clinical review. Clinical Psychology Review, 31(2), 203-212. doi: https://doi.org/10.1016/j.cpr.2010.04.009

Egan, S. J., Watson, H. J., Kane, R. T., McEvoy, P., Fursland, A., \& Nathan, P. R. (2013). Anxiety as a mediator between perfectionism and eating disorders. Cognitive Therapy and Research, 37(5), 905-913.doi: 10.1007/s10608-012-9516-х

Ewan, L. A., Middleman, A. B., \& Feldmann, J. (2014). Treatment of anorexia nervosa in the context of transsexuality: A case report. International Journal of Eating Disorders, 47(1), 112-115. doi: 10.1002/eat.22209

Fairburn, C. G., \& Harrison, P. J. (2003). Eating disorders. The Lancet, 361(9355), 407-416. doi: https://doi.org/10.1016/S0140-6736(03)12378-1

Fairburn, C. G., Cooper, Z., \& Shafran, R. (2003). Cognitive behaviour therapy for eating disorders: A "transdiagnostic" theory and treatment. Behaviour Research and Therapy, 41(5), 509-528. doi: https://doi.org/10.1016/S0005-7967(02)00088-8 
Fisher, A. D., Castellini, G., Bandini, E., Casale, H., Fanni, E., Benni, L., ... Rellini, A. H. (2014). Cross-sex hormonal treatment and body uneasiness in individuals with gender dysphoria. Journal of Sexual Medicine, 11(3), 709-719. doi: 10.1111/jsm.12413

Fitzsimmons-Craft, E. E. (2011). Social psychological theories of disordered eating in college women: Review and integration. Clinical Psychology Review, 31(7), 1224-1237. doi: https://doi.org/10.1016/j.cpr.2011.07.011

Garner, D. M. (1991). Eating disorder inventory-2. Odessa, FL: Psychological Assessment Resources.

Grogan, S. (2016). Body image: Understanding body dissatisfaction in men, women and children. New York: Routledge.

Harrison, A., Sullivan, S., Tchanturia, K., \& Treasure, J. (2009). Emotion recognition and regulation in anorexia nervosa. Clinical Psychology \& Psychotherapy, 16(4), 348-356. doi: $10.1002 /$ cpp. 628

Hayes, A. F. (2013). Introduction to mediation, moderation, and conditional process analysis: A regression-based approach. London/New York: Guilford Press.

Health Research Authority (HRA). (2013). Guidance for NHS Research Studies. London, UK: Health Research Authority.

House of Commons. (2016). Transgender Equality Inquiry: First report of session 2015-16. London: The Stationery Office Limited. Retrieved from: http://www.publications.parliament.uk/pa/cm201516/cmselect/cmwomeq/390/39002.htm IBM (2015). IBM SPSS Statistics for Windows, Version 23.0. Armonk, NY: IBM Corp. Jones, B. A., Haycraft, E., Murjan, S., \& Arcelus, J. (2016). Body dissatisfaction and disordered eating in trans people: A systematic review of the literature. International Review of Psychiatry, 28(1), 81-94. doi: http://dx.doi.org/10.3109/09540261.2015.1089217 
Jones, B. A., Brewin, N., Richards, C., Van Eijk, M., Stephenson-Allen, A., \& Arcelus, J. (2017). Investigating the outcome of the initial assessment at a national transgender health service: Time to review the process? International Journal of Transgenderism. Advance online publication. doi: http://dx.doi.org/10.1080/15532739.2017.1372838

Kanamori, Y., \& Cornelius-White, J. H. D. (2016). Big changes, but are they big enough? Healthcare professionals' attitudes toward transgender persons. International Journal of Transgenderism, 17 (3+4), 165-175.doi: http://dx.doi.org/10.1080/15532739.2016.1232628

Keel, P. K., Fulkerson, J. A., \& Leon, G. R. (1997). Disordered eating precursors in pre-and early adolescent girls and boys. Journal of Youth and Adolescence, 26(2), 203-216.

Khoosal, D., Langham, C., Palmer, B., Terry, T., \& Minajagi, M. (2009). Features of eating disorder among male-to-female transsexuals. Sexual and Relationship Therapy, 24(2), 217-229.doi: http://dx.doi.org/10.1080/14681990903082161

McCreary, D. R., \& Sasse, D. K. (2000). An exploration of the drive for muscularity in adolescent boys and girls. Journal of American College Health, 48(6), 297-304. doi: http://dx.doi.org/10.1080/07448480009596271

McClain, Z., \& Peebles, R. (2016). Body image and eating disorders among lesbian, gay, bisexual, and transgender youth. Pediatric Clinics, 63(6), 1079-1090. doi: http://dx.doi.org/10.1016/j.pcl.2016.07.008

Menard, S. (1995). Applied logistic regression analysis. Sage university paper series on quantitative applications in the social sciences, 07-106. Thousand Oaks, CA: Sage. Mepham, N.J., Bouman, W.P., Arcelus, J., Hayter, M., \& Wylie, K.R. (2014). People with Gender Dysphoria who self prescribe Cross Sex Hormones: Prevalence, Sources and Side Effects Knowledge. Journal of Sexual Medicine, 11(12), 2995-3001. 
Millet, N., Longworth, J., \& Arcelus, J. (2017). Prevalence of anxiety symptoms and disorders in the transgender population: A systematic review of the literature. International Journal of Transgenderism, 18(1), 27-38. doi: http://dx.doi.org/10.1080/15532739.2016.1258353

Morgan, J. F. \& Arcelus, J. (2009). Body image in gay and straight men: A qualitative study. European Eating Disorders Review, 17(6), 435-443. doi:10.1002/erv.955

Myers, R. (1990). Classical and modern regression with applications. Second edition. Boston, MA: Duxbury.

Nevonen, L., Clinton, D., \& Norring, C. (2006). Validating the EDI-2 in three Swedish female samples: eating disorders patients, psychiatric outpatients and normal controls. Nordic Journal of Psychiatry, 60(1), 44-50. doi: http://dx.doi.org/10.1080/08039480500504537

Pallant, J. (2010). SPSS survival manual: A step by step guide to data analysis using SPSS. Maidenhead: Open University Press.

Polivy, J., \& Herman, C. P. (2002). Causes of eating disorders. Annual Review of Psychology, 53(1), 187-213. doi: https://doi.org/10.1146/annurev.psych.53.100901.135103

Puccio, F., Fuller-Tyszkiewicz, M., Youssef, G., Mitchell, S., Byrne, M., Allen, N., \& Krug, I. (2017). Longitudinal Bi-directional Effects of Disordered Eating, Depression and Anxiety. European Eating Disorders Review, 25(5), 351-358. doi: 10.1002/erv.2525.

Rosenberg, M. (1965). Society and the adolescent self-image. Princeton, NJ: Princeton University Press.

Robins, R. W., Hendin, H. M., \& Trzesniewski, K. H. (2001). Measuring global self-esteem: Construct validation of a single-item measure and the Rosenberg Self-Esteem Scale. Personality and Social Psychology Bulletin, 27(2), 151-161. 
Scheim, A.I., Zong, X., Giblon, R., \& Bauer, G.R. (2017). Disparities in access to family physicians among transgender people in Ontario, Canada. International Journal of Transgenderism, 18(3), 343-352.

Snaith, R. P. (2003). The hospital anxiety and depression scale. Health and Quality of Life Outcomes, 1(1), 29-33. doi: https://doi.org/10.1186/1477-7525-1-29

Stice, E., \& Shaw, H. E. (2002). Role of body dissatisfaction in the onset and maintenance of eating pathology. Journal of Psychosomatic Research, 53(5), 985-993. doi: https://doi.org/10.1016/S0022-3999(02)00488-9

Tchanturia, K., Larsson, E., \& Adamson, J. (2016). Brief Group Intervention Targeting Perfectionism in Adults with Anorexia Nervosa: Empirically Informed Protocol. European Eating Disorders Review, 24(6), 489-493. doi: 10.1002/erv.2467.

van de Grift, T.C., Elaut, E., Cerwenka, S.C., Cohen-Kettenis, P.T., De Cuypere, G., RichterAppelt, H., \& Kreukels, B.P.C. (2017). Effects of Medical Interventions on Gender Dysphoria and Body Image: A Follow-Up Study. Psychosomatic Medicine, 79(7), 815823. doi: https://dx.doi.org/10.1097\%2FPSY.0000000000000465

van de Grift, T.C., Kreukels, B.P.C., Elfering, L., Özer, M., Bouman, M-B., Buncamper, M., ... Mullender, M. (2016). Body Image in Transmen: Multidimensional measurement and the effects of mastectomy. Journal of Sexual Medicine, 13(11), 1778-1786.

doi: http://dx.doi.org/10.1016/j.jsxm.2016.09.003

Wang, S. B., Lydecker, J. A., \& Grilo, C. M. (2017). Rumination in Patients with BingeEating Disorder and Obesity: Associations with Eating-Disorder Psychopathology and Weight-bias Internalization. European Eating Disorders Review, 25(2), 98-103. doi: 10.1002/erv.2499. 
Watson, R. J., Veale, J. F., \& Saewyc, E. M. (2017). Disordered eating behaviors among transgender youth: Probability profiles from risk and protective factors. International Journal of Eating Disorders, 50(5), 515-522. doi: 10.1002/eat.22627

Winston, A. P., Acharya, S., Chaudhuri, S., \& Fellowes, L. (2004). Anorexia nervosa and gender identity disorder in biologic males: A report of two cases. International Journal of Eating Disorders, 36(1), 109-113. doi: 10.1002/eat.20013

Witcomb, G. L., Bouman, W. P., Brewin, N., Richards, C., Fernandez-Aranda, F., \& Arcelus, J. (2015). Body image dissatisfaction and eating-related psychopathology in trans individuals: A matched control study. European Eating Disorders Review, 23(4), 287-293. doi: 10.1002/erv.2362

Zeiler, M., Waldherr, K., Philipp, J., Nitsch, M., Dür, W., Karwautz, A., and Wagner, G. (2016). Prevalence of Eating Disorder Risk and Associations with Health-related Quality of Life: Results from a Large School-based Population Screening. European Eating Disorders Review, 24(1), 9-18. doi: 10.1002/erv.2368.

Zigmond, A. S., \& Snaith, R. P. (1983). The hospital anxiety and depression scale. Acta Psychiatrica Scandinavica, 67(6), 361-370. 
Eating disorder psychopathology in transgender people

Table 1: Socio-demographic characteristics for the whole sample, for participants who have taken cross-sex hormones, and for participants who have not taken cross-sex hormones

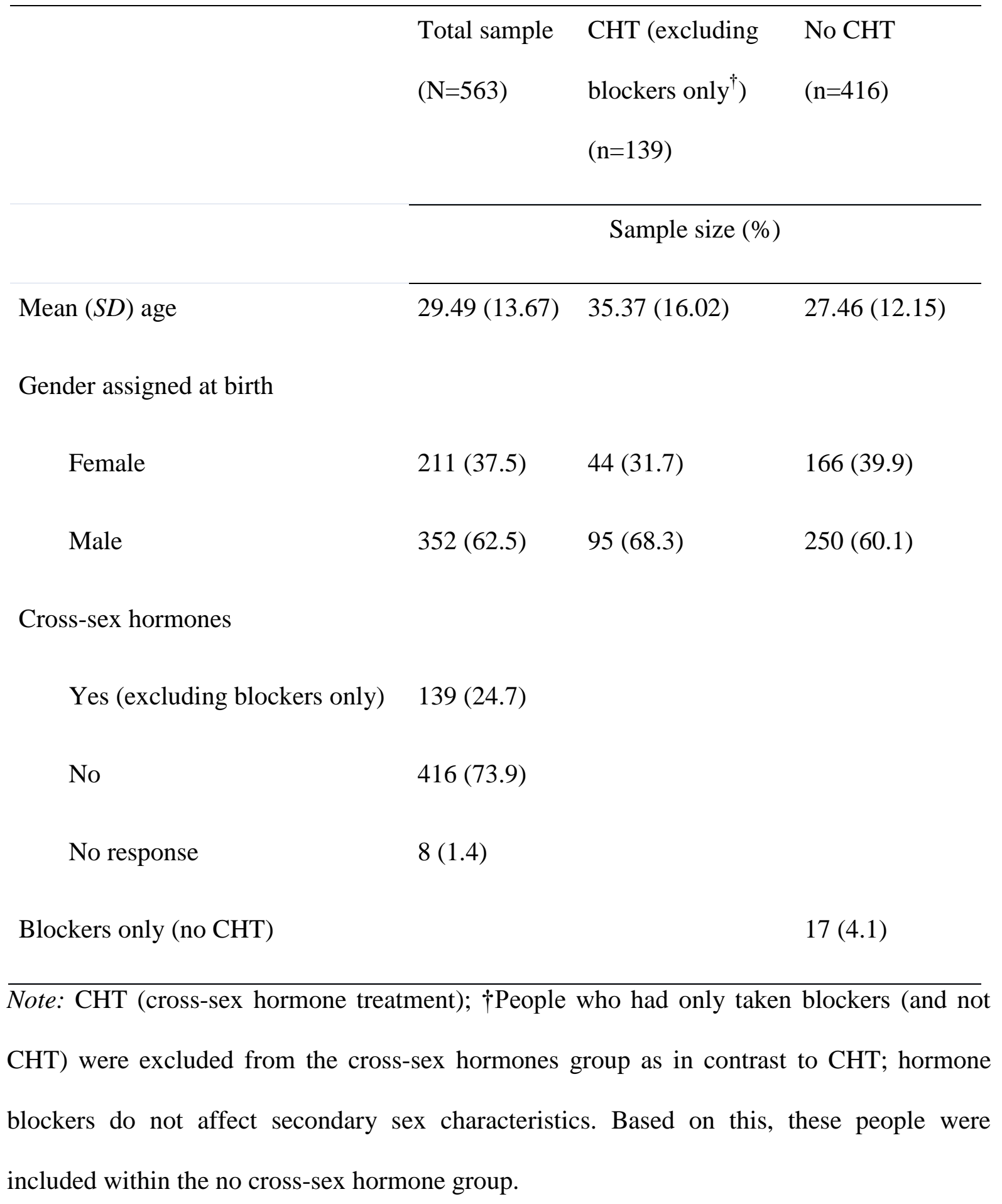


Table 2: Means, standard deviations (SD) and Mann Whitney U tests of difference between people who have taken CHT and those who have not for all study variables

\begin{tabular}{|c|c|c|c|c|c|}
\hline & \multirow{2}{*}{$\begin{array}{l}\text { No CHT } \\
(n=416)\end{array}$} & \multirow{2}{*}{$\begin{array}{l}\text { CHT }(\mathrm{n}=139) \\
\mathrm{M}(S D)\end{array}$} & \multicolumn{3}{|c|}{ Mann-Whitney U } \\
\hline & & & $\mathrm{U}$ & $\mathrm{Z}$ & $p$ \\
\hline Age & $27.46(12.15)$ & $35.37(16.02)$ & 20126.50 & -5.38 & .001 \\
\hline Drive for thinness & $3.87(4.95)$ & $2.82(4.07)$ & 25207.50 & -2.14 & .019 \\
\hline Bulimia & $1.87(3.54)$ & $0.96(2.32)$ & 24178.00 & -2.99 & .002 \\
\hline Body dissatisfaction & $12.13(6.96)$ & $9.62(6.83)$ & 22368.00 & -3.86 & .001 \\
\hline Interpersonal distrust & $5.66(4.60)$ & $3.56(3.86)$ & 20609.50 & -4.72 & .001 \\
\hline Anxiety & $8.27(4.31)$ & $6.45(4.00)$ & 21021.50 & -4.39 & .001 \\
\hline Depression & $7.22(3.88)$ & $5.18(3.48)$ & 19270.50 & -5.37 & .001 \\
\hline Self-esteem & $14.74(6.52)$ & $19.01(6.49)$ & 17849.00 & -6.31 & .001 \\
\hline Perfectionism & $5.10(4.19)$ & $4.88(3.86)$ & 27975.50 & -.28 & .410 \\
\hline
\end{tabular}

$\overline{\mathrm{CHT}}$ (cross-sex hormone treatment) 
Eating disorder psychopathology in transgender people

Table 3: One-tailed Spearman's Rho correlations between drive for thinness, bulimia and the $\underline{\text { study variables for people who have not taken } \mathrm{CHT}(\mathrm{n}=416)}$

Drive for Bulimia

thinness

\begin{tabular}{lll}
\hline Age & .01 & -.12 \\
Male gender assigned at birth $\dagger$ & -.05 & -.07 \\
Female gender assigned at birth $\dagger$ & .05 & .07 \\
Body dissatisfaction & $.48^{* * *}$ & $.31^{* * *}$ \\
Perfectionism & $.24^{* * *}$ & $.26^{* * *}$ \\
Interpersonal distrust & $.27 * * *$ & $.30^{* * *}$ \\
Anxiety & $.35^{* * *}$ & $.36^{* * *}$ \\
Depression & $.30^{* * *}$ & $.28^{* * *}$ \\
Self-esteem & $-.37 * * *$ \\
\hline VHT (cross-sex hormone treatment) & $-.48^{* * *}$ \\
\hline
\end{tabular}


Eating disorder psychopathology in transgender people

Table 4: Stepwise regression models showing the significant risk factors of (i) drive for thinness and (ii) bulimia for people who have not taken CHT ( $n=416)$

\begin{tabular}{|c|c|c|c|c|c|}
\hline & $F$ & $R^{2}$ & beta & SE beta & $\beta$ \\
\hline Drive for thinness & $57.32 * * *$ & .30 & & & \\
\hline Body dissatisfaction & & & .31 & .03 & $.43 * * *$ \\
\hline Perfectionism & & & .18 & .05 & $.16 * * *$ \\
\hline Anxiety & & & .18 & .05 & $.16^{* * *}$ \\
\hline Bulimia & $32.86^{* * *}$ & .25 & & & \\
\hline Self-esteem & & & -.13 & .03 & $-.24 * * *$ \\
\hline Perfectionism & & & .15 & .04 & $.18 * * *$ \\
\hline Body dissatisfaction & & & .08 & .02 & $.16 * * *$ \\
\hline Anxiety & & & .12 & .05 & $.14 * *$ \\
\hline
\end{tabular}

$* p<0.05, * * p<0.01, * * * p<0.001$

CHT (cross-sex hormone treatment) 
Table 5: Perfectionism, self-esteem and anxiety as potential mediators of the relationship between body dissatisfaction and eating disorder psychopathology (drive for thinness and bulimia) in people who have not taken CHT ( $\mathrm{n}=416$ )

Regression model unstandardized beta coefficients for paths $a, b, c$ and $a b$ and bootstrapped lower and upper

confidence intervals

\begin{tabular}{|c|c|c|c|c|c|c|c|}
\hline Outcome variable & Mediator in model & $a($ beta $)(\mathrm{X}-\mathrm{M})$ & $b$ (beta) (M-Y) & $\begin{array}{l}c(\text { beta })(X- \\
Y ; \text { direct } \\
\text { effect })\end{array}$ & $\begin{array}{l}\text { ab (beta) } \\
\text { (indirect } \\
\text { effect) }\end{array}$ & $\begin{array}{l}\text { Bootstrap } \\
\text { lower CI }\end{array}$ & $\begin{array}{l}\text { Bootstrap } \\
\text { upper CI }\end{array}$ \\
\hline \multicolumn{8}{|l|}{ Drive for thinness } \\
\hline & Model 1: Perfectionism & $.09 * *$ & $.23 * * *$ & $.33 * * *$ & .02 & .01 & .04 \\
\hline & Model 2: Anxiety & $.15^{* * *}$ & $.23 * * *$ & $.31 * * *$ & .03 & .02 & .06 \\
\hline \multicolumn{8}{|l|}{ Bulimia } \\
\hline & Model 3: Self-esteem & $-.39 * * *$ & $-.19 * * *$ & $.10 * *$ & .07 & .05 & .10 \\
\hline & Model 4: Perfectionism & $.09 * * *$ & $.29 * * *$ & $.14 * * *$ & .02 & .01 & .04 \\
\hline
\end{tabular}

${ }^{*} p<0.05,{ }^{*} p<0.01, * * * p<0.001, \mathrm{X}$-body dissatisfaction, M-mediator variable (perfectionism, self-esteem and anxiety), Y-outcome variable (drive for thinness or bulimia). CHT (cross-sex hormone treatment) 
Eating disorder psychopathology in transgender people

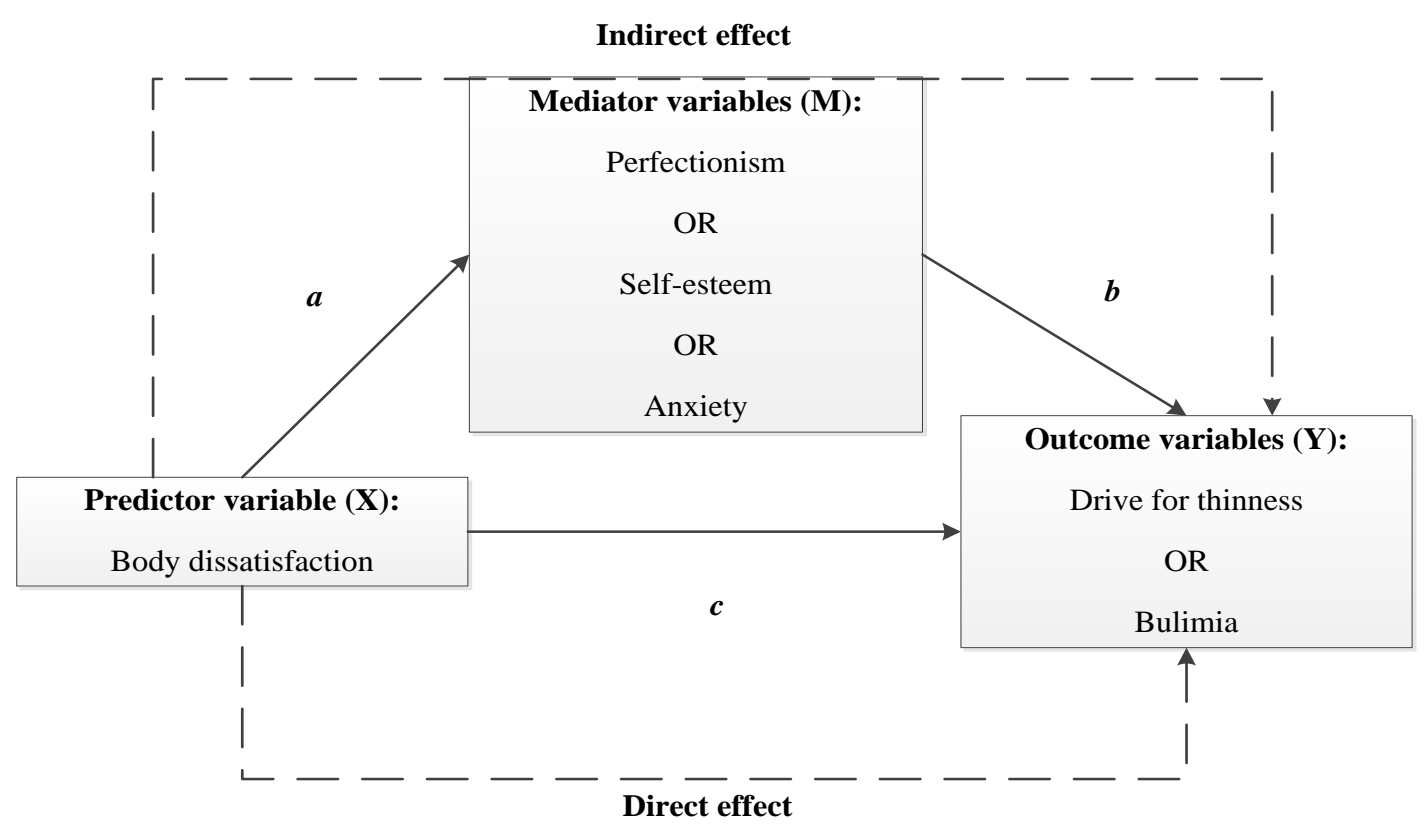

Figure 1: Mediation analyses for perfectionism and anxiety as mediators between body dissatisfaction and drive for thinness and, for self-esteem, perfectionism and anxiety as mediators between body dissatisfaction and bulimia 